\title{
Effect of fiber loading on tensile properties of cocoa pod husk fibers reinforced thermoplastic polyurethane composites
}

\begin{abstract}
In this study, cocoa (Theobroma cacao) pod husk (CPH) fiber reinforced themoplastic polyurethane (TPU) was prepared by melt blending method using Haake Polydrive R600 internal mixer. The composites were prepared with different fiber loading: $20 \%, 30 \%$ and $40 \%$ (by weight), with the optimum processing parameters: $190^{\circ} \mathrm{C}, 11 \mathrm{~min}$, and $40 \mathrm{rpm}$ for temperature, time and speed, respectively. Five samples were cut from the composite sheet. Mean value was taken for each composite according to ASTM standards. Increase of fibre loading showed increase in tensile strength and modulus and decreasing trend of strain.
\end{abstract}

Keyword: Cocoa pod fibers; Natural fiber composites; Tensile properties; Thermoplastic polyurethane 